\title{
Relief of heterogeneous symptoms after successful gall bladder stone lithotripsy and complete stone disappearance
}

\author{
U Stölzel, Ch Koszka, B Wölfer, U Kleine, W Pommerien, E O Riecken
}

\begin{abstract}
The symptoms of 100 patients with gall bladder stone disease were prospectively analysed before and after successful treatment with extracorporeal shock wave lithotripsy (ESWL) and oral bile acids. This is of considerable clinical interest because complaints after cholecystectomy persist in $21-47 \%$ of patients (postcholecystectomy syndrome). Before ESWL, 37 patients had unspecific abdominal symptoms (feeling of fullness and pressure, or slight pain, or both, in the right upper abdomen, flatulence, nausea, or food intolerance) and 63 patients had typical biliary symptoms (severe steady pain of more than 15 minutes and less than five hours duration in the right upper abdomen, in some cases radiating to the epigastrium or the back) either exclusively or with unspecific abdominal complaints. After becoming stone free, 72 of 100 patients lost the symptoms they had before treatment. All 28 patients with persisting symptoms had unspecific abdominal symptoms before treatment (exclusively unspecific symptoms and unspecific plus typical biliary symptoms). In contrast, patients with typical biliary symptoms before ESWL lost these in $95 \%$ of all cases. Although the anatomical structures are left intact after ESWL, the percentages of stone free patients with persisting symptoms are similar to those after cholecystectomy.

(Gut 1994; 35: 819-821)
\end{abstract}

Department of

Gastroenterology,

Klinikum Steglitz, Free

University of Berlin,

Germany

U Stölzel

Ch Koszka

B Wölfer

E O Riecken

Department of Surgery,

Krankenhaus Berlin

Moabit, Berlin, Germany

U Kleine

Department of

Gastroenterology,

Krankenhaus am Urban

Berlin, Berlin, Germany

W Pommerien

Correspondence to:

Dr U Stölzel, Department of Gastroenterology, Klinikum Steglitz, Free University of

Berlin, 1000 Berlin 45,

Hindenburgdamm 30

Germany.

Accepted for publication

20 October 1993
Surgical removal of the gall bladder is at present the most effective method for the treatment of symptomatic gall bladder stone disease. Nevertheless, retrospective and prospective studies have shown that $21-47 \%$ of the patients after conventional cholecystectomy still complained of abdominal symptoms (postcholecystectomy syndrome)..$^{1-7}$ Many causes for persistent complaints after cholecystectomy has been discussed. ${ }^{37}$ Since 1986 a novel non-invasive treatment using extracorporeal shock waves has been used. ${ }^{8-12}$ Extracorporeal shock wave lithotripsy (ESWL) of gall bladder stones leaves the anatomical structures intact thus preserving the physiological basis of bile secretion. Therefore, it is of considerable interest to analyse the complaints of stone free patients after ESWL of gall bladder stones. In this study, we report the symptoms of 100 patients before and after becoming stone free using ESWL and adjuvant litholysis with oral bile acids.
Patients and methods

\section{PATIENTS}

Between July 1989 and August 1993, we prospectively examined 100 patients, who remained 5 (4) months (mean (SD)), (median 3; range 1-17) stone free after ESWL. The mean age was 50 (13) years (median 49; range, 24-84). Seventy six patients were female and 24 were male with body mass indices (mean (SD)) of 27 (5) (median 26; range, 16-32). Solitary gall stones of $5 \mathrm{~mm} \leqslant 20 \mathrm{~mm}$ in diameter were found in 65 cases, stones of $20 \mathrm{~mm} \leqslant 30 \mathrm{~mm}$ in diameter in 14 cases, 21 patients had multiple gall stones (10 patients with two to three gall stones $\leqslant 30 \mathrm{~mm}$ in total diameter, 11 patients with 3-10 stones $\leqslant 30 \mathrm{~mm}$ in total diameter). All patients showed radiolucent concrements in the plain abdominal $x$ ray films, the gall bladder wall was sonographically inconspicuous, and the volume reduction of the gall bladder after stimulation with a meal was greater than $40 \%$.

Before treatment, an abdominal sonography with examination of liver, gall bladder, bile ducts, pancreas, kidney, spleen, and abdominal vessels was performed in all cases.

Oesophagogastroduodenoscopy was performed in patients with unspecific symptoms alone or in combination with biliary symptoms. The following laboratory tests were performed during all examinations: blood cell count, prothrombin time, potassium, sodium, creatinin, amylase, lipase, alanine aminotransferase, aspartate aminotransferase, alkaline phosphatase, and $\gamma$-glutamyltransferase urine analysis.

Patients were excluded from the study if erosions or ulcerations could be detected during oesophagogastroduodenoscopy, if laboratory values deviating from the normal range were found, and if previous abdominal conditions such as pancreatitis, liver disease, or diverticulitis - or coronary heart disease existed.

\section{SYMPTOMS}

All patients treated had abdominal symptoms before ESWL. They were interviewed before ESWL and asked to provide information about abdominal pain including location, radiation of pain, description of pain, quality with regard to character, duration, severity, concomitant symptoms, and provoking or relieving factors. We discriminated between patients with unspecific symptoms (feeling of fullness and pressure, or slight pain, or both in the right upper abdomen, flatulence, nausea, or food 
intolerance) and patients with typical biliary symptoms (severe steady pain of more than 15 minutes and less than five hours duration in the right upper abdomen, in some cases radiating to the epigastrium or the back), either exclusively or with unspecific symptoms. ${ }^{13}$

\section{LITHOTRIPSY AND MEDICAL TREATMENT}

Ninety one patients were treated by one to four sessions (median 1 ; mean $1.3(0.6)$ ) with the lithotriptor MPL 9000 (Dornier). Technical details of the applied method have been published previously. ${ }^{14}$ On average (mean (SD)) 2463 (1440) shock waves (median 1782; range, 657-9100) were directed under continuous sonographic control to the stone(s) positioned in the focus. Nine patients were treated by one to two sessions (median 1; mean $1.5(0.5)$ ) with a Lithostar Ultra lithotriptor (Siemens) using (mean (SD)) 3940 (2615) shock waves (median 3067; range 900-9100). Before each session, 95 patients were given $40 \mathrm{mg}$ promethacine by mouth plus $7 \cdot 5-15 \mathrm{mg}$ piritramide intraveneously or $50 \mathrm{mg}$ pethidine plus $2.5-5 \mathrm{mg}$ midazolam intraveneously for analgesia. All patients received adjuvant oral litholytic treatment with ursodeoxycholic acid and chenodeoxycholic acid each $7.5 \mathrm{mg} / \mathrm{kg}$ of body weight per day until two months after the gall bladder was stone free.

\section{FOLLOW UP}

Sonographic examinations were performed four weeks after ESWL and at intervals of two or three months thereafter. Patients were classified stone free only if sonographic examinations at two different occasions showed identical results. After an interval (mean (SD)) of 23 (11) months (median 25; range, 6-45) with a stone free gall bladder shown sonographically symptoms were assessed again with a mailed questionnaire that was combined with a telephone interview. All patients with persisting symptoms were examined again sonographically. Where there was persisting biliary symptoms endoscopic retrograde cholangiopancreatography (ERCP) was proposed; one patient refused ERCP.

\section{Results}

The Table lists the symptoms before and after successful gall stone lithotripsy. Before ESWL, 37 patients had unspecific abdominal complaints and 63 patients had typical biliary symptoms, either exclusively $(n=10)$ or with unspecific abdominal complaints $(n=53)$ (Table).

Symptoms before and after successful gall bladder stone lithotripsy and complete stone disappearance

\begin{tabular}{|c|c|c|c|c|c|}
\hline Symptoms & $\begin{array}{l}\text { Before } \\
\text { ESWL }\end{array}$ & $\begin{array}{l}\text { Exclusively biliary } \\
\text { symptoms in stone } \\
\text { free patients }(n)\end{array}$ & $\begin{array}{l}\text { Biliary and } \\
\text { unspecific } \\
\text { symptoms in stone } \\
\text { free patients }(n)\end{array}$ & $\begin{array}{l}\text { Unspecific } \\
\text { symptoms in stone } \\
\text { free patients }(n)\end{array}$ & $\begin{array}{l}\text { Relief of } \\
\text { symptoms in } \\
\text { stone free } \\
\text { patients }(\%)\end{array}$ \\
\hline $\begin{array}{l}\text { Biliary and } \\
\text { unspecific } \\
\text { Unspecific } \\
\text { Total }\end{array}$ & $\begin{array}{r}63 \\
37 \\
100\end{array}$ & $\begin{array}{l}0 \\
0 \\
0\end{array}$ & $\begin{array}{l}3 \\
0 \\
3\end{array}$ & $\begin{array}{l}12 \\
13 \\
25\end{array}$ & $\begin{array}{l}76 \\
64 \\
72\end{array}$ \\
\hline
\end{tabular}

$\mathrm{n}=$ Number of patients with the corresponding symptoms.
Duration of biliary symptoms in 62 patients before treatment was (mean (SD)) 25 (32) months (median 12; range, $0 \cdot 5-120$ ) and frequency was (mean (SD)) $3 \cdot 2(4 \cdot 6)$ episodes per month (median 2; range, $0 \cdot 02-14$ ). In 89 patients the duration and frequency of unspecific symptoms before treatment were (mean (SD)) 26 (33) months (median 12; range, $0 \cdot 5-120$ ) and (mean (SD)) $8 \cdot 3(9 \cdot 8)$ episodes per month (median 12; range, $0.02-30)$. Seventy two patients reported satisfactory outcome - that is, complete relief of all pretreatment symptoms at the time of examination. The 10 patients with biliary symptoms only before ESWL lost their symptoms in all cases. In 24 of 37 patients with unspecific symptoms before ESWL, the symptoms disappeared after the gall bladder was stone free. Of the 53 patients with both typical biliary and unspecific symptoms, 50 lost their biliary symptoms and 38 lost their unspecific symptoms after ESWL. Of 90 patients with unspecific symptoms (exclusively unspecific symptoms and unspecific plus typical biliary symptoms), 62 (69\%) lost their symptoms. In three patients the biliary and the unspecific symptoms persisted. In one of these cases, a bile duct stone could be diagnosed by ERCP; during this procedure, a papillotomy was performed and the stone was removed. In the second case, a previously undetected stenosis of the distal bile duct, which was possibly caused by chronic pancreatitis, could be shown by ERCP. One patient refused ERCP.

\section{Discussion}

Retrospective and prospective studies showed that $21-47 \%$ of the patients after conventional cholecystectomy still complained of abdominal symptoms (postcholecystectomy syndrome). ${ }^{1-7}$

Using the non-invasive method of ESWL, Lee et al found $30 \%$ of stone free patients with persistent complaints. ${ }^{15}$ In this report, however, the investigators did not distinguish between patients complaining of typical biliary or unspecific abdominal symptoms, or both before ESWL and after becoming stone free. Furthermore they did not use bile acids for litholysis. We report here a similar figure of $28 \%$ of patients with persistent abdominal complaints after successful ESWL in stone free patients; in addition, we found that all these patients had unspecific abdominal symptoms before treatment (exclusively unspecific symptoms or unspecific plus typical biliary symptoms). Ninety five per cent of patients with typical biliary symptoms (exclusively typical biliary symptoms or typical biliary plus unspecific symptoms) were cured of their biliary symptoms. Stone recurrence as a possible cause of persisting symptoms was excluded by sonography. In one patient, a bile duct stone and in another patient, a bile duct stenosis was detected as the cause of persisting biliary symptoms. Although the anatomical structures are left intact after ESWL, the percentages of patients with persisting complaints are similar to those after cholecystectomy. Therefore, it can be assumed that persisting complaints after cholecystectomy are more a question of the causal relation between pretreatment symptoms and gall stones than a consequence of the removed 
gall bladder. A comparison, however, between residual symptoms after these two therapies is limited as only patients with sonographically inconspicuous gall bladder wall and intact contractility are suitable for ESWL. Therefore, with high risk patients included, only $10-23 \%$ of all referred patients can be treated with lithotripsy. ${ }^{121+16-18}$ It should also be considered that especially anxious or highly sensitive patients may prefer a non-invasive technique such as ESWL.

Unspecific complaints such as feeling of bloating, pressure, or slight pain in the right upper abdomen, flatulence, nausea, or food intolerance including fat intolerance are not specific for cholelithiasis. ${ }^{19-20}$ One study even reported that these symptoms were of no predictive value at all for the diagnosis of cholelithiasis. ${ }^{21}$ Because of these findings it was concluded that gall bladder stones are not responsible for the above described unspecific abdominal symptoms.

In contrast we found that more than two thirds of our patients with unspecific abdominal symptoms before treatment lost these complaints after becoming stone free using ESWL and adjuvant litholysis with oral bile acids. The disappearance of these complaints after non-invasive gall bladder stone treatment increases the probability of a causal relation between the complaints and the gall stones. We think that these findings are helpful to predict the individual therapeutical success of ESWL in patients, in whom, after a thorough diagnostic procedure, only gall bladder stones were found to explain unspecific abdominal symptoms. Only a controlled study design, which should include sham treatment, would be suitable to prove the relation between gall stone disappearance after ESWL and response of symptoms. Such a trial, however, is difficult to carry out and has not been done so far.

We thank Elisabeth Zsifko for helping to analyse these data by computer.
1 Bodvall V, Overgard B. Computer analysis of postcholecystectomy biliary tract symptoms. Surg Gynecol Obstet 967; 124: 723-32.

2 Gunn A, Keddie N. Some clinical observations on patients with gallstones. Lancet 1972; ii: $239-41$.

3 Tondelli P, Gyr K, Stalder GA, Allgower M. Post surgical syndromes: the biliary tract. Clin Gastroenterol 1974; 8: 487504.

4 Ros E, Zambon D. Postcholecystectomy symptoms. A prospective study of gall stone patients before and two years after surgery. Gut 1987; 28: 1500-4.

5 Rhodes M, Lennard TW. Satisfaction after cholecystectomy. Lancet. 1988; i: 599.

6 Bates T, Ebbs SR, Harrison M, A'Hern RP. Influence of cholecystectomy on symptoms. Br F Surg 1991; 78: 964-7.

7 Jorgensen T, Teglbjerg JS, Wille-Jorgenson P, Bille T,

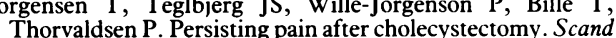
Thorvaldsen P. Persisting pain aftroenterol 1991; 26: 124-8.

8 Sauerbruch T, Delius M, Paumgartner G, Holl J, Wess O, Weber W, et al. Fragmentation of gallstones by extracorporeal shock waves. $N$ Englf Med 1986; 318: 818-22.

9 Schoenfield LJ, Berci G, Carnovale RL, Casarella W, Caslowitz P, Chumley D, et al. The effect of ursodiol on the efficacy and safety of extracorporal shock-wave lithotripsy of gallstones. The Dornier National Biliary Lithotripsy Study. NEngl f Med 1990; 323: 1239-45.

10 Ell C, Kerzel W, Schneider HT, Benninger J, Wirtz P, Domschke W, et al. Piezoelectric lithotripsy: stone disintegration and follow up results in patients with symptomatic gration and follow up results in patients with symptomat

11 Darzi A, El Sayed E, O'Morain C, Tanner WA, Keane FB. Piezoelectric lithotripsy for gallstones: analysis of results in patients with extended selection. Br f Surg 1991; 78: 163-6.

12 Sackmann M, Pauletzki J, Sauerbruch T, Holl J, Schelling G, Paumgartner G. The Munich gallbladder lithotripsy study. Results of the first 5 years with 711 patients. Ann Intern Med 1991; 114: 290-6.

13 Paumgartner G, Carr-Locke DL, Roda E, Thistle JL. Biliary stones: non-surgical therapeutic approach. Gastroenterology International 1988; 1: 17-24.

14 Stölzel U, Lenz K, Gregor M, Arntz R, Tung LC, Riecken EO. Kombinierte Therapie von Gallenblasensteinen mit extracorporealen Stosswellen und Gallensäuren: Ergebnisse in Abhängigkeit von Steindurchmesser und Steinzahl. Z Gastroenterol 1992; 30: 121-4.

15 Lee SH, Burhenne HJ. Persistence of symptoms after gall bladder clearance with cholecystolithotripsy. Gut 1991; 32: b36-8.

16 Stölzel U, Koszka C, Gregor M, Ziegler K, Zimmer Th, Riecken EO. Lithotripsy of an impacted calcified stone in the cystic duct accompanied by cholecystitis in severe Crohn's disease. Gut 1993; 34: 1145-7.

17 Rambow A, Staritz M, Klose P, Thelen M, Meyer zum Büschenfelde KH. Extracorporale Stosswellenlithotripsie von Gallenblasensteinen: Wie viele Patienten sind geeignet? Dtsch Med Wochenschr 1989; 114: 895-8.

18 Albert MB, Fromm H, Borstelmann R, Shehan CM, Gicking R. Successful outpatient treatment of gallstones with piezoelectric lithotripsy. Ann Intern Med 1990; 113: 164-6.

19 Fromm H, Malavolti M. Cholelithiasis. Current therapy in gastroenterology and liver disease. Toronto: B C Decker, 1986; 2: $422-4$.

20 Schoenfield LJ, Carulli N, Dowling RH, Ransohoff D, Sama $\mathrm{C}$, Wolpers C. Asymptomatic gallstones: definition and C, Wolpers C. Asymptomatic gallstones: definition

21 Jorgensen T. Abdominal symptoms and gallstone disease: an epidemiological investigation. Hepatology 1989; 9: 856-60. 